\title{
Pulmonary Function and Response to Exercise in Cystic Fibrosis
}

\author{
S. GODFREY and MARGARET MEARNS \\ From the Institute of Diseases of the Chest, and Queen Elizabeth Hospital for Children, London
}

Godfrey, S., and Mearns, M. (1971). Archives of Disease in Childhood, 46, 144. Pulmonary function and the response to exercise in cystic fibrosis. Results of physiological studies at rest and during exercise in 41 patients with cystic fibrosis of the lungs are presented. The patients were evenly distributed by age between 5 and 21 years, and were grouped into 3 clinical grades corresponding to mild, moderate, and fairly severe disease.

There was a linear relation between tests of lung mechanics such as the $\mathrm{FEV}_{1}$ and the MVV and the clinical grading. These tests also correlated well with one another. Certain tests, notably those reflecting parenchymal damage such as the $\mathrm{TL}_{\mathrm{co}}$ showed a non-linear relation to clinical severity, deteriorating more rapidly from grade 2 to 3 than from grade 1 to 2 .

A very specific pattern emerged of enlargement of physiological deadspace even in the mildest cases. As the disease progressed, venous admixture occurred at rest, which was initially returned to normal by exercise. In the severest cases, there was never a complete return to normal. These changes may be explicable in terms of pathology.

Exercise was limited by pulmonary mechanics. Total ventilation was increased to accommodate the increased deadspace so that arterial $\mathrm{PcO}_{2}$ remained normal. Cardiac output was normal.

Adequate evaluation of the pulmonary physiological abnormality could be obtained by measuring the $\mathrm{FEV}_{1}$ (or MVV), TL $\mathrm{To}$, and maximum work load possible, but very useful extra information is obtained by measuring arterial saturation (or venous admixture) and dead space.

Cystic fibrosis is now recognized as the commonest cause of chronic pulmonary disease in childhood, but with improvements in treatment it can be expected that $50 \%$ or more of patients will reach the age of 20 years (Warwick and Pogue, 1969). It is accepted that the earlier treatment is started the better the results, and it is therefore of great importance to be able to diagnose and evaluate the condition and to assess the value of various therapeutic regimens. Studies have shown a good correlation between clinical severity and a variety of tests of lung mechanics (Doershuk et al., 1965; Beier et al., 1966; Mearns, 1968; Featherby et al., 1969). These authors are generally agreed that there is airways obstruction which increases as the patient's condition deteriorates. There is less

Received 25 September 1970. agreement about the ability to transfer CO from lungs to blood (the 'diffusing capacity' $\mathrm{TL}_{\mathrm{co}}$ ).

In order to study pulmonary efficiency in terms of the balance of ventilation and perfusion within the lung, conventional methods require catheterization of pulmonary and systemic arteries. Though such studies have been performed in patients with cystic fibrosis (Goldring et al., 1964), they are particularly disturbing to children and it may be argued that such procedures are not clinically justifiable. Moreover in cystic fibrosis, when lung damage occurs, a prominent symptom is breathlessness on exertion. Since it is particularly difficult to exercise the patients to a reasonable level during catheterization, this feature of the disease has not been fully studied physiologically.

Recently, techniques have been developed in this department for the investigation of the pulmo- 


\section{Pulmonary Function and Response to Exercise in Cystic Fibrosis}

nary and cardiac response to exercise in children by the indirect $\left(\mathrm{CO}_{2}\right)$ Fick method (Godfrey and Davies, 1970). These techniques do not involve cardiac or systemic catheterization and are quite acceptable to the children (Godfrey, 1970a). To obtain further information on the physiological disturbances in cystic fibrosis and to see which investigations were the most useful in assessment and management, we have studied a group of patients using these techniques.

\section{Subjects}

Studies were made on 41 patients aged 6 to $21 \cdot 8$ years. There were 24 male and 17 female patients and their distribution by age and height centile is given in Fig. 1. The diagnosis of cystic fibrosis was confirmed

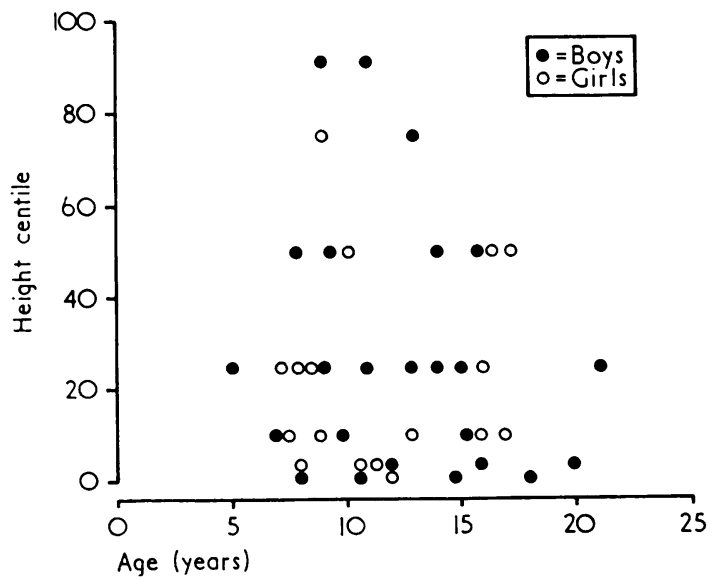

FIG. 1.-Distribution of subjects by age and height centiles.

in all these patients by finding the sweat sodium to be above $70 \mathrm{mEq} / \mathrm{l}$. The patients were divided into three grades based on clinical and radiological findings as previously described (Jackson and Young, 1960). In brief these grades are as follows.

Grade I: Good general health. May have occasional attack of bronchitis or short periods with cough and sputum. Chest $x$-ray normal or may be a minimal degree of thickened bronchial wall pattern (17 patients).

Grade II: Good general health, with respiratory symptoms as above, but chest $x$-ray showing localized change (12 patients).

Grade III: Persistent pulmonary infection with purulent sputum with or without abnormal findings in the lungs on clinical examination, chest $x$-ray showing generalized changes and with or without impaired general health (12 patients).

Of the 41 children, 31 have been personally followed up at one clinic by M.M. The other 10 children regularly attended another clinic. The clinical assessment of these 10 children was based on the same criteria as the others.

\section{Methods}

The patients spent the whole day in the department as outpatients. Adequate rest periods were allowed between studies.

Simple spirometry was performed with a wet spirometer (P.K. Morgan Limited) and the forced expiratory volume in one second $\left(\mathrm{FEV}_{1}\right)$ and the forced vital capacity (FVC) were calculated. Lung volumes and airways resistance (Raw) were measured in a whole body plethysmograph by the methods of DuBois, Botelho, and Comroe (1956b) and DuBois et al. (1956a). The ratio of the residual volume of the total lung capacity (RV/TLC) as determined in the plethysmograph was calculated. The transfer factor for carbon monoxide $\left(\mathrm{TL}_{\mathrm{CO}}\right)$ was measured by the steady state method of Bates, Boucot, and Dormer (1955).

Exercise studies were performed in exactly the same fashion as described previously for normal children (Godfrey and Davies, 1970). In brief, the patient performed simple progressive exercise seated on a cycle ergometer (Lode), with the work load being increased every minute by an increment depending on height. Pulse and ventilation were recorded. After a rest, a steady state exercise test was performed in which the child was studied at rest and at one-third and two-thirds of the maximum work load achieved in the progressive test. At each level of the steady state test expired gas was collected in a Tissot spirometer and analysed for $\mathrm{CO}_{2}$ and $\mathrm{O}_{2}$. Arterialized ear lobe blood was sampled and analysed by the method of Godfrey et al. (1971). The mixed venous $\mathrm{PCO}_{2}$ was measured by a rebreathing method using prepared $\mathrm{CO}_{2}$ in $\mathrm{O}_{2}$ mixtures (Jones et al., 1967). All data including the electrocardiograph were recorded continuously on a chart recorder (Mingograf 81). The crude data from the studies were fed into a digital computer using a programme written to calculate exercise test results allowing for necessary corrections (Godfrey, 1970b).

After the exercise study, the maximum voluntary ventilation (MVV) was determined by the 15-second sprint method (Clark et al., 1969). The best of several attempts at various frequencies was taken.

Calculations. From the progressive exercise test, the highest level of work completed $\left(\mathbb{W}_{\max }\right)$ and the pulse and ventilation at this level (MExV) were noted. In the steady state test the results at the highest work load were used. Ventilation (Vent), gas exchange, and cardiac output were calculated. The physiological dead space (VD) corrected for instrument dead space $(53 \mathrm{ml})$ was calculated by the equation of Bohr (1890) and the venous admixture (VA) breathing air by the shunt equation (Riley and Cournand, 1949). No correction for theoretical diffusion gradients was applied. No results were available for venous admixture breathing high $\mathrm{O}_{2}$ because the ear blood $\mathrm{PO}_{2}$ is unreliable at high 
levels (personal observations). The VA was also calculated for the steady state rest period.

All values except VA were calculated as percentage of the expected normal values based on height. Normal values for lung volumes and resistance data and for exercise results were those obtained in this laboratory (Godfrey, Kamburoff, and Nairn, 1970b; Godfrey et al., 1970a); the results of Weng and Levison (1969) were used for $\mathrm{TL}_{\mathrm{co}}$.

The abbreviations used in the text appear in Table I.

\section{Results}

The relation between a number of tests and the clinical grade are shown in Table II. Regression equations are given in Table III. There was good agreement between tests of lung mechanics and the clinical grading, airways obstruction increasing with the progression of the disease. Thus the $\mathrm{FEV}_{1}$, the FVC, and the MVV all decreased
TABLE I

List of Abbreviations Used

\begin{tabular}{|c|c|}
\hline $\begin{array}{l}\text { TLco }_{\text {co }} \\
\text { FEV }_{1}\end{array}$ & $\begin{array}{l}\text { Transfer factor ('diffusing capacity') for carbon monoxide } \\
\text { Forced expired volume in } 1 \text { second }\end{array}$ \\
\hline FVC & Forced vital capacity \\
\hline Raw & Airway resistance \\
\hline $\mathrm{RV}$ & Residual volume \\
\hline TLC & Total lung capacity \\
\hline MVV & Maximum voluntary ventilation \\
\hline$W_{\max }$ & Highest workload completed in progressive exercise test \\
\hline MExV & $\begin{array}{l}\text { Highest minute ventilation achieved in progressive exercise } \\
\text { test }\end{array}$ \\
\hline Vent & Minute ventilation in steady state exercise \\
\hline VD & Physiological dead space \\
\hline VA & Venous admixture ('right-to-left shunt') \\
\hline
\end{tabular}

significantly from grade 1 to 2 and from grade 2 to 3 . The high values for MVV in grade 1 are due to the number of small children in this grade because the SE of the estimate of the expected value is large and the regression on size less exact

TABLE II

Values of Various Measurements in Relation to Clinical Grade: Mean, Standard Error of Mean (SEM) and Number of Observations ( $n$ )

\begin{tabular}{|c|c|c|c|c|c|c|}
\hline & & \multicolumn{3}{|c|}{ Clinical Grade } & \multicolumn{2}{|c|}{ Significance of Differences } \\
\hline & & 1 & 2 & 3 & Grades 1-2 & Grades 2-3 \\
\hline $\begin{array}{l}\text { Age (yr) } \\
\text { FEV }_{\mathbf{J}}(\% \text { expected) }\end{array}$ & $\begin{array}{c}\text { Mean } \\
\text { SEM } \\
\mathbf{n} \\
\text { Mean }\end{array}$ & $\begin{array}{l}9 \cdot 51 \\
0 \cdot 72 \\
17 \\
85\end{array}$ & $\begin{array}{l}12 \cdot 61 \\
0 \cdot 78 \\
12 \\
67\end{array}$ & $\begin{array}{r}15 \cdot 40 \\
1 \cdot 01 \\
12 \\
49\end{array}$ & ++ & + \\
\hline 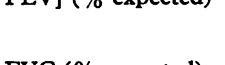 & SEM & $\begin{array}{r}3 \\
17\end{array}$ & $\begin{array}{r}6 \\
12\end{array}$ & $\begin{array}{r}4 \\
12\end{array}$ & ++ & + \\
\hline FVC (\% expected) & $\begin{array}{c}\text { Mean } \\
\text { SEM } \\
\mathbf{n}\end{array}$ & $\begin{array}{r}96 \\
4 \\
17\end{array}$ & $\begin{array}{r}82 \\
4 \\
12\end{array}$ & $\begin{array}{r}70 \\
4 \\
12\end{array}$ & + & + \\
\hline RV/TLC (\%) & $\begin{array}{c}\text { Mean } \\
\text { SEM }\end{array}$ & $\begin{array}{r}37 \\
3 \\
11\end{array}$ & $\begin{array}{r}38 \\
3 \\
11\end{array}$ & $\begin{array}{r}54 \\
3 \\
12\end{array}$ & NS & +++ \\
\hline$T L_{c o}(\%$ expected $)$ & $\begin{array}{c}\text { Mean } \\
\text { SEM } \\
\text { n }\end{array}$ & $\begin{array}{r}99 \\
6 \\
13\end{array}$ & $\begin{array}{r}89 \\
5 \\
11\end{array}$ & $\begin{array}{r}70 \\
6 \\
12\end{array}$ & NS & + \\
\hline Raw (\% expected) & $\begin{array}{c}\text { Mean } \\
\text { SEM } \\
\mathbf{n}\end{array}$ & $\begin{array}{r}251 \\
19 \\
11\end{array}$ & $\begin{array}{r}244 \\
25 \\
11\end{array}$ & $\begin{array}{r}355 \\
30 \\
12\end{array}$ & NS & ++ \\
\hline MVV (\% expected) & $\begin{array}{c}\text { Mean } \\
\text { SEM } \\
\mathbf{n}\end{array}$ & $\begin{array}{r}116 \\
6 \\
17\end{array}$ & $\begin{array}{r}89 \\
4 \\
12\end{array}$ & $\begin{array}{r}67 \\
4 \\
12\end{array}$ & +++ & +++ \\
\hline$W_{\max }(\%$ expected $)$ & $\begin{array}{c}\text { Mean } \\
\text { SEM } \\
\mathbf{n}\end{array}$ & $\begin{array}{r}97 \\
6 \\
15\end{array}$ & $\begin{array}{r}82 \\
5 \\
12\end{array}$ & $\begin{array}{r}69 \\
4 \\
12\end{array}$ & + & + \\
\hline $\begin{array}{l}\text { Ventilation } \\
\text { (\% expected) }\end{array}$ & $\begin{array}{c}\text { Mean } \\
\text { SEM } \\
\mathbf{n}\end{array}$ & $\begin{array}{r}136 \\
4 \\
16\end{array}$ & $\begin{array}{r}141 \\
7 \\
12\end{array}$ & $\begin{array}{r}150 \\
5 \\
12\end{array}$ & NS & NS \\
\hline VD (\% expected) & $\begin{array}{c}\text { Mean } \\
\text { SEM } \\
\mathbf{n}\end{array}$ & $\begin{array}{r}226 \\
16 \\
17\end{array}$ & $\begin{array}{r}266 \\
17 \\
12\end{array}$ & $\begin{array}{r}329 \\
20 \\
12\end{array}$ & NS & + \\
\hline VA (rest) (\%) & $\begin{array}{c}\text { Mean } \\
\text { SEM } \\
\mathbf{n}\end{array}$ & $\begin{array}{r}3.8 \\
0.5 \\
14\end{array}$ & $\begin{array}{r}5 \cdot 8 \\
0.9 \\
12\end{array}$ & $\begin{array}{c}10 \cdot 3 \\
1 \cdot 1 \\
12\end{array}$ & + & +++ \\
\hline VA (exercise) (\%) & $\begin{array}{c}\text { Mean } \\
\text { SEM } \\
\text { n }\end{array}$ & $\begin{array}{l}2 \cdot 3 \\
0 \cdot 3 \\
13\end{array}$ & $\begin{array}{l}2 \cdot 7 \\
0 \cdot 2 \\
12\end{array}$ & $\begin{array}{l}5 \cdot 6 \\
0 \cdot 7 \\
12\end{array}$ & NS & +++ \\
\hline
\end{tabular}

Note: Abbreviations are those used in the text but ventilation refers to steady state ventilation. Significance of differences between grades 1 and 2 and grades 2 and 3 are shown $(+=0.05>p>0.01 ;++=0.01>p>0.0025 ;+++=0.0025>p)$. 
TABLE III

Regression Equations for Results

\begin{tabular}{|c|c|c|c|c|c|c|c|}
\hline $\mathbf{Y}$ & $\mathbf{B}$ & $\mathbf{x}$ & $\mathbf{M}$ & SEY & $\mathbf{r}$ & $\mathbf{n}$ & Sig. \\
\hline $\begin{array}{l}\text { MVV } \\
\text { TLco } \\
W_{\max } \\
\text { VD } \\
\text { VD } \\
\text { VD } \\
\text { Vent. } \\
\text { MExV }\end{array}$ & $\begin{array}{r}0.86 \\
0.57 \\
0.55 \\
-1.98 \\
2.86 \\
13.82 \\
0.08 \\
0.36\end{array}$ & $\begin{array}{l}\text { FEV }_{1} \\
\text { FEV } 1 \\
\text { MVV } \\
\text { FEV } 1 \\
\text { RV/TLC } \\
\text { VA } \\
\text { VD } \\
\text { MVV }\end{array}$ & $\begin{array}{c}34 \\
48 \\
33 \\
405 \\
152 \\
177 \\
120 \\
25 \cdot 5\end{array}$ & $\begin{array}{r}21 \\
20 \\
20 \\
64 \\
68 \\
135 \\
71 \\
12 \cdot 3\end{array}$ & $\begin{array}{l}0 \cdot 67 \\
0 \cdot 54 \\
0 \cdot 71 \\
0 \cdot 56 \\
0 \cdot 48 \\
0 \cdot 39 \\
0 \cdot 30 \\
0 \cdot 66\end{array}$ & $\begin{array}{l}39 \\
34 \\
37 \\
39 \\
32 \\
36 \\
38 \\
35\end{array}$ & $\begin{array}{c}+++ \\
++ \\
+++ \\
+++ \\
+++ \\
++ \\
+ \\
+++\end{array}$ \\
\hline
\end{tabular}

Note: $\mathrm{Y}=$ dependent variable, $\mathrm{x}=$ independent variable, $\mathrm{B}=$ regression coefficient, $\mathrm{SEY}=$ standard error of estimate of $\mathrm{y}, \mathrm{r}=$ correlation coefficient, $n=$ degrees of freedom. Abbreviations are those used in the text. Vent. is ventilation in submaximal steady state exercise and MExV is maximum ventilation achieved at breaking point of simple progressive exercise. Code for significance of regressions is same as in Table II.

in such subjects. There was also good correlation between the various tests of lung mechanics, the

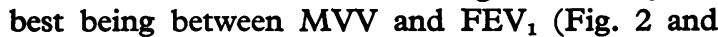
Table III). There was no significant difference between grade 1 and grade 2 for airways resistance but there was a significant deterioration from grade 2 to grade 3.

The transfer factor for $\mathrm{CO}$ was normal in grade 1 and was reduced in grade 2 and further reduced in grade 3. The reduction between grades was only significant between grades 2 and 3 . There was a significant correlation between $\mathrm{TL}_{\mathrm{co}}$ and FEV $_{1}$ (Fig. 3 and Table III).

The ability to exercise was related to clinical grade, $W_{\max }$ falling significantly from grade 1 to

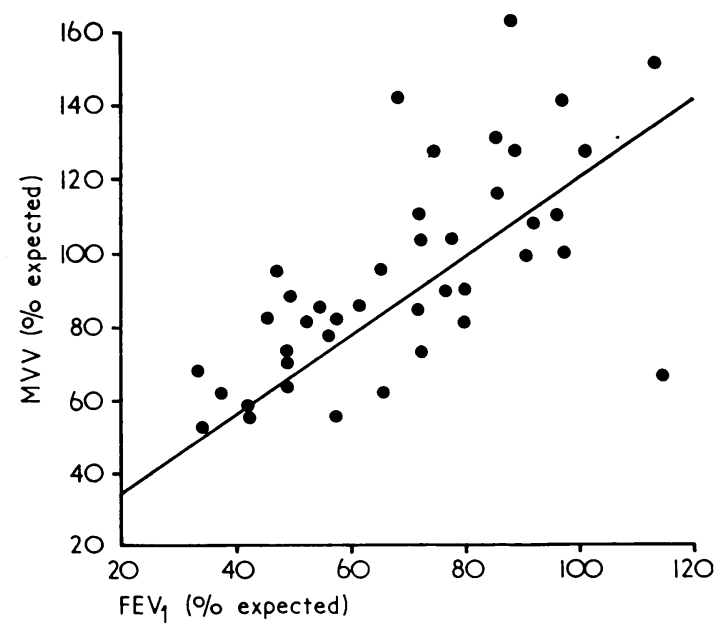

FIG. 2.-The relation between maximum voluntary ventilation $(M V V)$ and the forced expired volume in 1 second $\left(F E V_{1}\right)$ both expressed as percentage of expected values. grade 2 and grade 2 to grade 3 (Table II). In the mildest grade $\mathbb{W}_{\max }$ was within the normal range (mean \pm 18 watts). When comparing $W_{\max }$ with the tests of lung mechanics, the best correlation by far was that with MVV (Fig. 4 and Table III). There was also a close correlation between maximum exercise ventilation attained at the limit of the simple progressive exercise (MExV) and MVV (Table III), but it should be noted that exercise ventilation exceeded the MVV at all levels below an MVV of $501 . / \mathrm{min}$ (Fig. 5).

Physiological dead space (VD) was considerably enlarged in all but one child in which it was $122 \%$. In all but 7 children it was over twice the expected value. Even in the fittest children (grade 1) the mean value for VD was $226 \%$. Though it increased progressively with the clinical grading (Table II) the difference between grade 1 and grade 2 was not

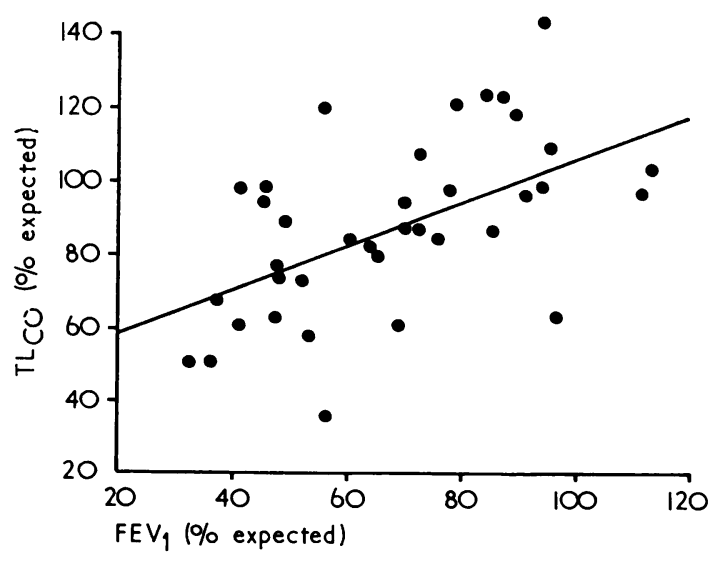

Fig. 3.-The relation between the CO transfer factor $\left(T L_{\mathrm{co}}\right)$ and the $F E V_{1}$ both expressed as percentage of expected value. 


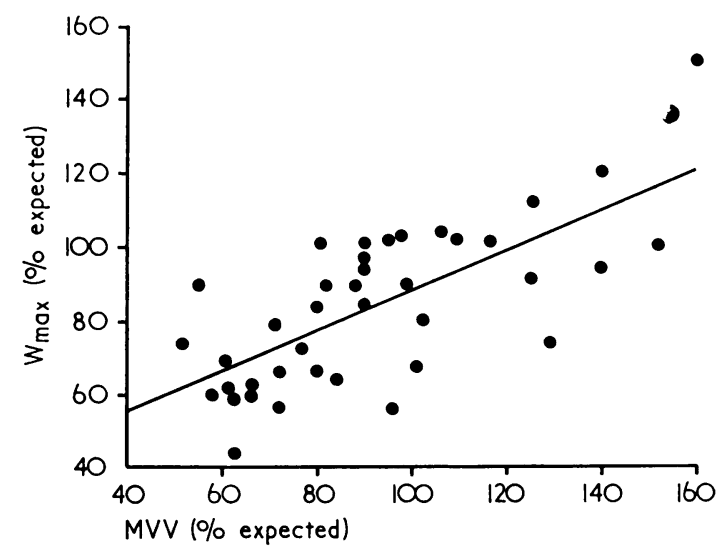

FIG. 4.-The relation between the highest work level attained on simple progressive exercise $\left(W_{\max }\right)$ and the $M V V$ both expressed as percentage of expected values.

significant but that between grades 2 and 3 was significant. The enlargement of VD correlated well with the mechanical evidence of airways obstruction as indicated by the FEV 1 or RV/TLC (Fig. 6 and 7 and Table III).

Venous admixture (VA) at rest increased significantly from grade 1 to 2 and from grade 2 to 3 , but the greatest difference occurred from grade 2 to 3 (Table II). It was rather poorly

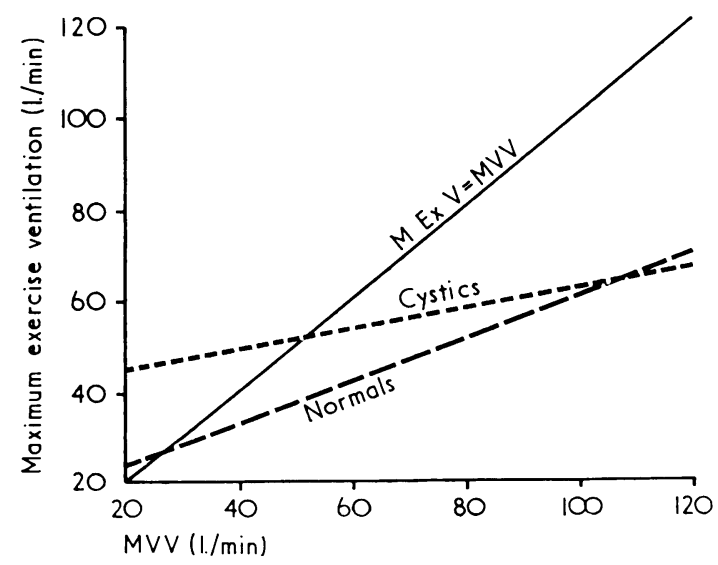

Fig. 5.-The relation between the highest ventilation attained on simple progressive exercise $(M E x V)$ and the $M V V$. The line labelled 'cystics' refers to the present study and shows that exercise ventilation exceeds the $M V V$ up to 50 l./min. The line labelled 'normals' refers to the normal values found in this laboratory. The line of identity where exercise ventilation $=M V V$ is also shown.

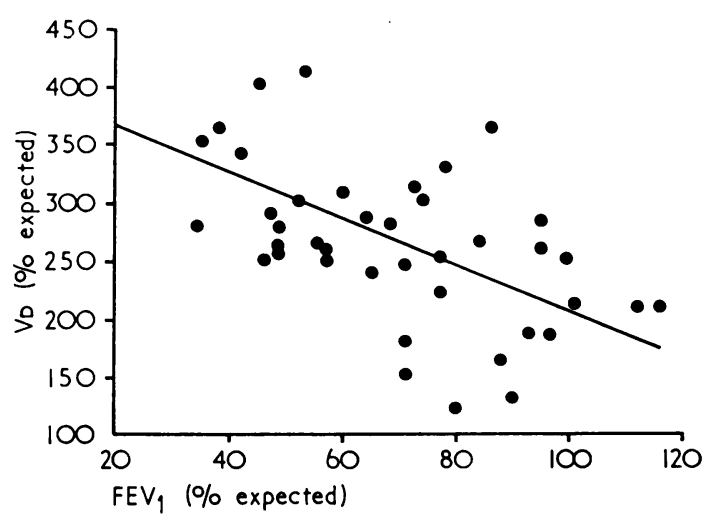

FIG. 6.-The relation between dead space $(V D)$ and the $F E V_{1}$ both expressed as percentage of expected values.

related to mechanical tests but was significantly correlated with VD (Fig. 8 and Table III). On exercise, the VA fell in all groups but it was still above normal $(<3 \%)$ for children in grade 3 (Table II). The significant difference in VA between grades 1 and 2 was lost on exercise, but persisted between grades 2 and 3 .

Ventilation and pulse rate on exercise were poor guides to clinical state and did not correlate with the maximum working capacity $\left(\mathbb{W}_{\max }\right)$. However, steady state ventilation was above normal in all grades (Table II). It was actually raised in all but one patient, a 7-year-old boy who had a VD of $95 \mathrm{ml}$, the expected value being $78 \mathrm{ml} \pm 22$ (SE). In the group as a whole there was a significant correlation for the rise of steady state ventilation with the rise of VD (Table III).

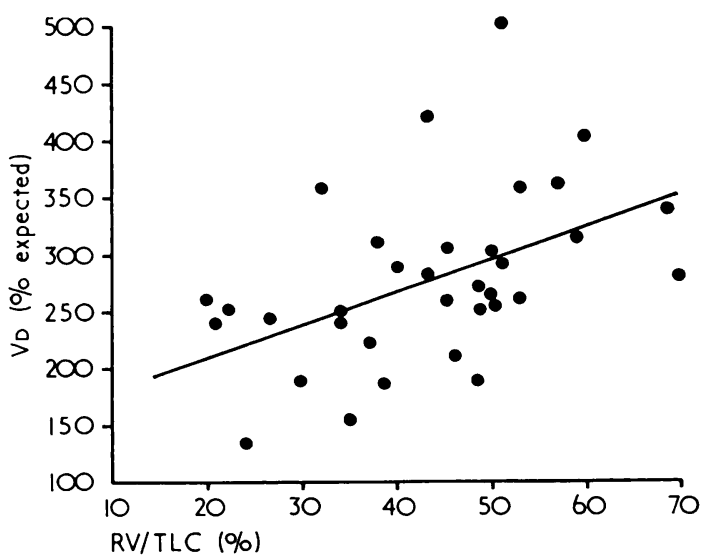

FIG. 7.-The relation between $V_{D}$ as percentage expected and the RVITLC ratio. 


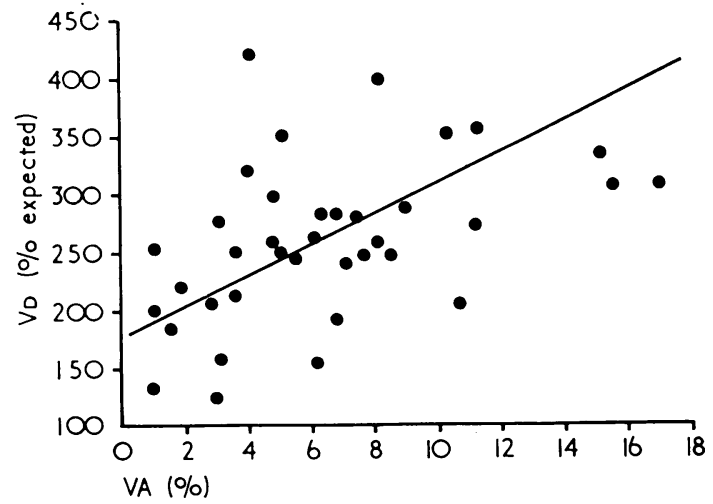

Fig. 8.-The relation between $V D$ as percentage expected and the venous admixture (or right-to-left shunt).

Arterial $\mathrm{PCO}_{2}$ was normal in all but the two eldest patients in whom it was 54 and $49 \mathrm{mmHg}$ respectively.

Cardiac output was within normal limits in all studies.

\section{Discussion}

Many studies have now shown the correlation between clinical state and tests of airways obstruction in cystic fibrosis, and this subject has recently been fully discussed (International Cystic Fibrosis Conference, 1969). We have confirmed these findings though our method of clinical grading did not employ the Shwachman rating because this rating uses many subjective criteria developed in the Boston Clinic. We felt it would be unreliable arbitrarily to use such a score or to modify it and preferred to use the grading developed in London over a long period. In general terms, the grading proposed by Jackson and Young (1960) which has been used here can be compared with the description of Shwachman and Kulczycki (1958); our grade 1 was approximately equivalent to a Shwachman score of 71 and over, grade 2 to a score of 56 to 70 , and grade 3 to a score of 55 or less.

A number of parameters showed little difference between the mild and moderate patients but were significantly worse in grade 3 than grade 2 . This applied to the enlargement of $R V$, the fall in $\mathrm{TL}_{\mathrm{co}}$, the enlargement of $\mathrm{VD}$ and the increase of VA on exercise (Table II). Though this might imply that the grading was not even from 1 to 3, many other tests such as the $\mathrm{FEV}_{1}$ and the MVV showed a smooth deterioration from grade to grade. This finding could imply that recurrent infections result in progressive damage to airways with increasing obstruction, and that parenchymal

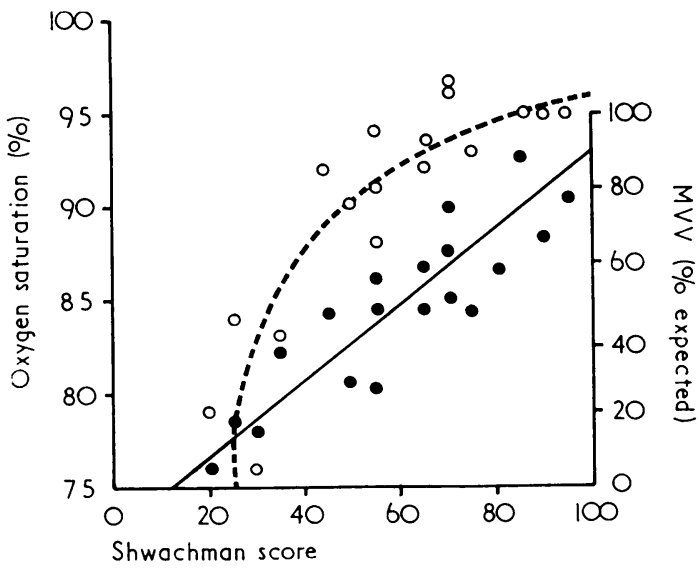

FIG. 9.-The relation between MVV (solid symbols and right ordinate) and Shwachman score and between arterial saturation (open symbols and left ordinate) and Shwachman score, from the data of Featherby et al. (1969). The lines have been drawn as best fits to the data.

damage, as shown by abnormalities in the $\mathrm{TL}_{\mathrm{co}}$, VD, and VA, does not occur until a certain level of airways obstruction has been reached.

This discontinuity of some tests and not others can also be seen in the data of Beier et al. (1966) where there was an excellent linear correlation for FEV $_{1}$ with the Shwachman score but the arterial oxygen saturation (which reflects VA almost linearly over this range) only became abnormal at the lower levels of the clinical score (Fig. 9). The junction between our grades 2 and 3 corresponds approximately to a Shwachman score of 55, and it is just at this level that significant desaturation was noted by Beier et al. (1966) (see Fig. 9). We also found that significant VA appeared on passing from grade 2 to grade 3 (Table II). Many studies have shown linear relation between arterial $\mathrm{Po}_{2}$ and clinical score (Matthews et al., 1969; Featherby et al., 1969). It should be realized however that linear correlations between arterial $\mathrm{Po}_{2}$ (as distinct from saturation) and clinical score may well be a physiological artefact because of the non-linear shape of the $\mathrm{O}_{2}$ dissociation curve. A relatively small increase of venous admixture in a wellsaturated patient will cause a larger fall of $\mathrm{Po}_{2}$ than a similar increase (and hence clinical deterioration) in a poorly saturated patient.

Our results have shown up a very consistent pattern of physiological disturbance in cystic fibrosis besides the well-known airways obstruction. In all our patients except one there was a marked increase in $V D$, even if the clinical condition was considered to be mild. We have not seen this 
pattern in other diseases. This increase in VD would necessitate an increase in total minute ventilation in order to keep alveolar ventilation constant; all but 2 patients adopted this pattern, as shown by the normal levels of arterial $\mathrm{PCO}_{2}$. Our mean arterial $\mathrm{PCO}_{2}$ was $38.6 \mathrm{mmHg}$, very close to the $39 \mathrm{mmHg}$ found by Featherby et al. (1969). They also noted an increase in VD and minute ventilation of a similar order to that found here in their resting studies of 34 children.

The necessity for hyperventilation may be partly responsible for exercise limitation because of the low ventilatory capacity in the more affected subjects. However, the MVV alone is a poor guide to exercise performance, especially in the lower regions as can be seen from the scatter of points in Fig. 4. This is probably because the patients were able to exceed their MVV on exercise (Fig. 5). Mellins et al. (1968) showed that patients with cystic fibrosis collapsed their airways and actually reduced airflow during forced expirations, once the driving pressure exceeded certain limits. This could well account for the difference between the MVV test in which high pressures are generated, and the maximum exercise ventilation in which the driving pressure may not have exceeded that needed for maximum flow. We have not noted an increase in peak expiratory flow rate during exercise in cystic fibrosis such as occurs in asthma (Godfrey, $1970 \mathrm{c})$ so that this mechanism is unlikely to be the cause of the greater ventilatory capacity. It is noteworthy that a defect of pulmonary vascularization which could result in a high overall ventilation/ perfusion ratio has been noted in pathological studies (Davies, 1969).

In chronic obstructive lung disease in adults areas of lung with high or low ventilation/perfusion ratios are usually present together (Jones, 1966), but in the present study we did not find the degree of VA seen in such adults, even in our most severe patients. Decrease of VA but increase of $\mathrm{PCO}_{2}$ on exercise is seen in the bronchial type of adult chronic airways obstruction, but desaturation occurs in the emphysematous type (Jones, 1966). Thus our patients with cystic fibrosis behave more like the bronchial type but differ from them in the degree of VA and in having a normal arterial $\mathrm{PCO}_{2}$ which does not increase on exercise.

The ability to transfer CO from the alveoli to blood depends on many factors besides alveolar membrane diffusion and is particularly liable to be abnormal in a situation where ventilation/perfusion imbalance occurs (Read, Read, and Pain, 1965). These authors noted that a wide range of $T L_{c o}$ values were obtained by the steady state method in adults with chronic airways obstruction if their arterial saturation was low, but more uniform results were obtained when saturation was high. This could well account for the various conflicting reports about $\mathrm{TL}_{\mathrm{co}}$ in cystic fibrosis (Beier et al., 1966; Featherby et al., 1969). Our own study shows that despite these theoretical objections and previous findings, $\mathrm{TL}_{\mathrm{co}}$ falls progressively with clinical deterioration, but like VD and VA (which it reflects), the greatest change occurs from grade 2 to grade 3.

We have not been able to make detailed comparisons between different treatment regimens in the present study, but 10 children were treated with a different regimen from the others, and yet we could detect no clear-cut physiological differences. Since they were also in the youngest age group, only time can tell if differences will appear. There was also a clear age difference between children in whom $V_{D}$ was under $300 \%$ expected $(9.9$ years \pm 1.0 SEM, $\mathbf{n = 1 6 )}$ and those in whom it was over $300 \%$ (13.6 years $\pm 1 \cdot 1$ SEM, $n=25$ ).

In conclusion we feel that there is a basic physiological defect in cystic fibrosis which appears as an enlargement of dead space. It is present even in the mildest affected patients. As the disease progresses, airways obstruction becomes more severe, and eventually venous admixture begins to appear. This initially returns to normal during exercise, but in later stages it is merely reduced. Hyperventilation, whether at rest or on exercise, is a compensation for the increased dead space. The ability to exercise is closely related to the ventilatory capacity and work is probably limited by pulmonary mechanics rather than circulatory factors or hypoxia. There appears to be a point in the clinical progress of the disease where a number of physiological measurements become abnormal or increase for the first time. Simple tests such as the $\mathrm{FEV}_{1}$ are adequate to follow the progression of the disease but the additional measurement of $\mathbb{W}_{\max }$ during simple progressive exercise gives a much better idea of reserve. The pattern of physiological disturbance is so characteristic that it could well serve as an aid to diagnosis in doubtful cases, and can be revealed by steady state exercise in the manner described without the use of cardiac or arterial catheterization. Some caution is needed, however, because we have recently studied an 8-year-old boy with chronic pulmonary infection due to hypo- $\gamma$-globulinaemia, who showed the pattern of enlarged dead space and increased venous admixture. It may be that the pattern can be produced by early widespread pulmonary infection. 


\section{Pulmonary Function and Response to Exercise in Cystic Fibrosis}

Based on this study we believe that adequate physiological assessment can be achieved with measurement of the $\mathrm{FEV}_{1}, \mathrm{TL}_{\text {co }}$, and $\mathrm{W}_{\max }$; the additional measurement of arterial saturation and VD improves the assessment considerably.

We thank Dr. D. Lawson, Dr. J. C. Batten, and Dr. A. D. M. Jackson for allowing us to study some of their patients; Professor Lynne Reid for her advice; and Dr. F. Prime and his staff for carrying out the measurements of $\mathrm{TL}_{\mathrm{co}}$ and those using the body plethysmograph. Dr. M. Mearns is in receipt of a grant from the Cystic Fibrosis Research Trust.

\section{REFERENCES}

Bates, D. V., Boucot, N. G., and Dormer, A. E. (1955). The pulmonary diffusing capacity in normal subjects. Fournal of Physiology, 129, 237.

Beier, F. R., Renzetti, A. D., Jr., Mitchell, M., and Watanabe, S. (1966). Pulmonary pathophysiology in cystic fibrosis. American Review of Respiratory Diseases, 94, 430.

Bohr, C. (1890). Ueber die Lungenathmung. Skandinavisches Archiv für Physiologie, 2, 236.

Clark, T. J. H., Freedman, S., Campbell, E. J. M., and Winn, R. R. (1969). The ventilatory capacity of patients with chronic airways obstruction. Clinical Science, 36, 307.

Davies, G. M. (1969). Lung damage, hypoplasia and right ventricular hypertrophy in cystic fibrosis. In Proceedings of the 5th International Cystic Fibrosis Conference, Churchill College, Cambridge, p. 350. Ed. by D. Lawson. Cystic Fibrosis Trust, London.

Doershuk, C. F., Matthews, L. W., Tucker, A. S., and Spector, S. (1965). Evaluation of a prophylactic and therapeutic program for patients with cystic fibrosis. Pediatrics, 36, 675.

DuBois, A. B., Botelho, S. Y., Bedell, G. N., Marshall, R., and Comroe, J. H., Jr. (1956a). A rapid plethysmographic method for measuring thoracic gas volume: a comparison with a nitrogen washout method for measuring functional residual capacity in normal subjects. Fournal of Clinical Investigation, 35, 322.

DuBois, A. B., Botelho, S. Y., and Comroe, J. H., Jr. (1956b). A new method for measuring airway resistance in man using a body plethysmograph: values in normal subjects and in patients with respiratory disease. Fournal of Clinical Investigation, 35, 327.

Featherby, E. A., Weng, T. R., Crozier, D. N., Duic, A., Reilly, B. J., and Levison, H. (1969). Dynamic and static lung volumes, blood-gas tensions and diffusing capacity in patients with cystic fibrosis. In Proceedings of 5th International Cystic Fibrosis Conference, Churchill College, Cambridge, p. 232. Ed. by D. Lawson. Cystic Fibrosis Trust, London.

Godfrey, S. (1970a). Physiological response to exercise in children with lung or heart disease. Archives of Disease in Childhood, 45, 534.

Godfrey, S. (1970b). The manipulation of the indirect Fick principle by a digital computer program for the calculation of exercise physiology results. Respiration, 27, 513.
Godfrey, S. (1970c). The physiological assessment of the effect of DSCG in the asthmatic child. Respiration, 27, Suppl., 353.

Godfrey, S., and Davies, C. T. M. (1970). Estimates of arterial $\mathrm{PCO}_{2}$ and their effect on the calculated values of cardiac output and dead space on exercise. Clinical Science, 39, 529.

Godfrey, S., Davies, C. T. M., Wozniak, E. R., and Barnes, C. (1970a). Cardiorespiratory response to exercise in normal children. Clinical. Science (in press)

Godfrey, S., Kamburoff, P. L., and Nairn, J. R. (1970b). Spirometry, lung volumes and airway resistance in normal children aged 5-18 years. British fournal of Diseases of the Chest, 64, 15.

Godrey, S., Wozniak, E. R., Courtenay Evans, R., and Samuels, C. S. (1971). The use of ear lobe blood instead of arterial blood at rest and during exercise. British fournal of Diseases of the Chest, 65, (in press).

Goldring, R. M., Fishman, A. P., Turino, G. M., Cohen, H. I., Denning, C. R., and Andersen, D. H. (1964). Pulmonary hypertension and cor pulmonale in cystic fibrosis of the pancreas. Fournal of Pediatrics, 65, 501.

International Cystic Fibrosis Conference (1969). Proceedings of the 5th International Cystic Fibrosis Conference, Churchill College, Cambridge. Ed. by D. Lawson, Cystic Fibrosis Trust, London.

Jackson, A. D. M., and Young, W. F. (1960). Cystic fibrosis of the pancreas. Long-term Observations of Chronic Diseases. Edited by F. Linneweh, p. 178. Springer, Berlin, Gottingen, and Heidelberg.

Jones, N. L. (1966). Pulmonary gas exchange during exercise in patients with chronic airway obstruction. Clinical Science, 31, 39.

Jones, N. L., Campbell, E. J. M., McHardy, G. J. R., Higgs, B. E. and Clode, M. (1967). The estimation of carbon dioxide pressure of mixed venous blood suring exercise. Clinical Science, 32, 311.

Matthews, L. W., Doershuk, C. F., McCalley, S. W., and Downs, T. (1969). The utilization of arterialized blood gas analysis in cystic fibrosis. In Proceedings of 5th International Cystic Fibrosis Conference, Churchill College, Cambridge, p. 264. Ed. by D. Lawson. Cystic Fibrosis Trust, London.

Mearns, M. B. (1968). Simple tests of ventilatory capacity in children with cystic fibrosis. Archives of Disease in Childhood, 43, 528.

Mellins, R. B., Levine, O. R., Ingram, R. H., Jr., and Fishman, A. P. (1968). Obstructive disease of the airways in cystic fibrosis. Pediatrics, 41, 560 .

Read, J., Read, D. J. C., and Pain, M. C. F. (1965). Influence of non-uniformity of the lungs on measurement of pulmonary diffusing capacity. Clinical Science, 29, 107.

Riley, R. L., and Cournand, A. (1949). 'Ideal' alveolar air and the analysis of ventilation-perfusion relationships in the lungs. fournal of Applied Physiology, 1, 825.

Shwachman, H., and Kulczycki, L. L. (1958). Long-term study of one hundred and five patients with cystic fibrosis. American Fournal of Diseases of Children, 96, 6.

Warwick, W. J., and Pogue, R. E. (1969). Computer studies in cystic fibrosis. In Proceedings of 5th International Cystic Fibrosis Conference, Churchill College, Cambridge, p. 320. Ed. by D. Lawson. Cystic Fibrosis Trust, London.

Weng, T. R., and Levison, H. (1969). Standards of pulmonary function in children. American Review of Respiratory Diseases, 99, 879 .

Correspondence to Dr. S. Godfrey, Institute of Diseases of the Chest, Fulham Road, London S.W.3. 